\title{
Çanakkale Onsekiz Mart Üniversitesi Tıp Fakültesi Dönem II ve III Öğrencilerinin Probleme Dayalı Öğrenime Karşı Tutumları
}

\author{
Attitude of Term II and III Students in Canakkale Onsekiz Mart University School of Medicine Towards \\ Problem Based Learning
}

\author{
Ayşegül Uludağ $\breve{g}^{1}$, Ahmet Uludă̆ ${ }^{2}$, Mustafa Saçar ${ }^{3}$, Yusuf Haydar Ertekin ${ }^{1}$, Murat Tekin ${ }^{1}$ \\ ${ }^{1}$ Aile Hekimliği Ana Bilim Dalı, Tıp Fakültesi, Çanakkale Onsekiz Mart Üniversitesi, Çanakkale, Türkiye \\ ${ }^{2}$ Tıbbi Genetik Ana Bilim Dalı, Tıp Fakültesi, Çanakkale Onsekiz Mart Üniversitesi, Çanakkale, Türkiye \\ ${ }^{3}$ Kalp ve Damar Cerrahisi Ana Bilim Dalı, Tıp Fakültesi, Çanakkale Onsekiz Mart Üniversitesi, Çanakkale, Türkiye
}

\section{ÖZET}

Giriş: Probleme dayalı öğrenme (PDÖ), karmaşık ve gerçek hayat problemlerini ortaya koyar ve öğrencinin çözüme giderken hem analiz, hem de sentez yeteneğini kullanmasını sağlar. Çözüme giderken belirlenen yolları öğrenci kendisi belirler ve kavram haritaları çıkararak öğrenmeyi sağlar. Probleme dayalı öğrenme problemi tanıma ve çözüm için bireylerin hem zihin hem de beceri yönünden aktif katılımlarını gerektiren, deneyime dayanan öğrenmeyi temsil eder. Bu çalışmada tıp fakültesinde uygulanan PDÖ oturumlarına karşı öğrencilerin tutumlarını değerlendirmek amaçlanmıştır.

Yöntem: Tanımlayıcı desendeki çalışmada Çanakkale Onsekiz Mart Üniversitesi Tıp Fakültesi Dönem II ve Dönem III öğrencilerine PDÖ oturumlarından hemen sonra probleme dayalı öğrenime karşı tutum ölçeği uygulanmıştır.

Bulgular: Çalışmaya 125 öğrenci katıldı. Probleme Dayalı Öğrenme Tutum Ölçeği (38 maddelik test) güvenirlik katsayısı (co-efficient alfa)=0,777 idi. PDÖ tutum ölçeğinde Dönem III öğrencilerinin grup çalışması alt grup puan ortalaması Dönem II öğrencilerinden anlamlı daha yüksekti $(p=0,050)$. Ders alt grup puan ortalaması Dönem II öğrencilerinde anlamlı daha yüksekti ( $p=0,036)$. Diğer alt grup puanları arasında anlamlı farklılık yoktu $(\mathrm{p}>0,05)$.

Sonuç: Öğrenciler PDÖ oturumlarına yönelik eğitim programlarına karşı olumlu tutumlar içinde oldukları gözlenmektedir. Dönem III öğrencileri grup çalışmasını dönem II öğrencilerine göre daha çok benimsemişlerdir. Grup çalışmasının benimsenmesinde daha fazla sayıda PDÖ oturum deneyimi yaşamak önemli olabilir. Bu çalışmanın yapıldı̆̆ı tıp fakültesinde sınırlı sayıda PDÖ oturumları düzenlendiğinden, tümüyle PDÖ ye karşı tutumlarının olumlu olduğundan bahsetmek hatalı olacaktır.

Anahtar kelimeler: Tutum, Probleme Dayalı Öğrenme, Öğrenciler, Tıp

\begin{abstract}
Introduction: Problem based learning (PBL) presents complicated real life problems and provides students to use analysing and synthesis abilities while reaching a solution. Students decide on solution pathways and produce concept maps on their own. Problem based learning represents experience-based learning which requires active participation for characterization and solution of the problem. In this study we aimed to evaluate the attitude of medical students to PBL sessions.

Methods: In this descriptive designed study, attitude scale towards PBL applied to the Canakkale Onsekiz Mart University School of Medicine term II and III students just after PBL sessions.

Results: One hundred twenty five students agreed to participate the study. Reliability co-efficient (co-efficient alfa) of PBL attitude scale (test with 38 clauses) was 0.777 . Group work sub-group mean score of term III students was significantly higher than term II students $(\mathrm{p}=0.050)$. Lesson subject sub-group mean score was significantly higher in term II students $(\mathrm{p}=0.036)$. There were no significant difference between other sup-groups ( $p>0.05$ ).

Conclusion: Students were found to be positive attitude to PBL sessions. Term III students adopted more than term II students. Experiencing more PBL sessions can be important for adopting group work. It would be a mistake to talk about positive attitude towards PBL because of the limited number of PBL sessions in this school of medicine.
\end{abstract}

Keywords: Attitude, Problem-Based Learning, Students, Medical

Başvuru / Submission: Şubat / February 22, 2016

Kabul / Acceptance: Nisan / April 05, 2016

Yazışma / Correspondence: Dr. Ayşegül Uludağ, Çanakkale Onsekiz Mart Üniversitesi, Tıp Fakültesi Hastanesi Yeni Binası, Aile Hekimliği AD. Kat 5, Öğretim Üyesi Odaları Merkez/Çanakkale.

Tel: +9028626359 50/2540

E-mail: draysegululudag@gmail.com

Atıf / Cite: Uludağ A, Uludağ A, Saçar M, Ertekin YH, Tekin M. Çanakkale Onsekiz Mart Üniversitesi Tıp Fakültesi dönem II ve III ögrencilerinin Probleme Dayalı Öğrenime karşı tutumları. Fam Pract Palliat Care. 2016;1(1):1-4 


\section{GíRiș}

Probleme dayalı öğrenme (PDÖ), 1960’ların ortalarında geleneksel öğretime alternatif olarak ortaya çıkmıştır. Tıp eğitiminde başlayan bu yaklaşım günümüzde daha başka birçok alanda uygulanmaktadır $(1,2)$. Probleme dayalı öğrenmede, öğrenciler konunun merkezinde amaçlanan hedef ve ilkeleri anlamalarına yardımcı olacak problemleri ele alır. Bu problemleri tanımlayarak çözüm sürecine girer. Bu anlamda PDÖ farklı yöntem kullanan bir öğretme stratejisi olarak tanımlanmaktadır. Genellikle "açıklama gerektiren bir durumu" ortaya koyan yazılı bir problem tanımlanır. Geleneksel yaklaşımdaki problem üzerinde çalışmak için önce bilgilerin verilmesinin yerine, PDÖ için "önce problemi öğrenme" yaklaşımı demek daha doğru olabilir $(3,4)$.

PDÖ, karmaşı ve gerçek hayat problemlerini ortaya koyar ve öğrencinin çözüme giderken hem analiz, hem de sentez yeteneğini kullanmasını sağlar. Çözüme giderken belirlenen yolları öğrenci kendisi belirler ve kavram haritaları çıkararak öğrenmeyi sağlar. Probleme dayalı öğrenme problemi tanıma ve çözüm için bireylerin hem zihin hem de beceri yönünden aktif katılımlarını gerektiren, deneyime dayanan öğrenmeyi temsil eder (5). Yapılandırmacı öğrenme anlayışının en önemli uygulamalarından birini temsil eden PDÖ, öğrencilerin problem çözme becerilerini geliştirmek ve konu ile ilgili temel bilgileri kazanmaları için bir bağlam olarak problemlerin kullanılması ile karakterize bir öğretme/öğrenme yaklaşımı olarak tanımlanabilir.

PDÖ, tıp eğitiminde sıkça kullanılan bir yöntem olmakla birlikte, Türkiye'de bazı tıp fakültelerinde mezuniyet öncesinde oldukça büyük bir yer etmektedir. Dokuz Eylül, Akdeniz, Pamukkale Tıp Fakültelerinde PDÖ, mezuniyet öncesinde eğitim programının temelini oluşturmaktadır. Fakültemiz Tıp Eğitiminde PDÖ eğitimini, normal entegre programın içinde her dönemde farklı sayıda uygulamaktadır. Üniversitemiz Tıp Fakültesinde 2013-2014 Eğitim-Öğretim yıllında Dönem I'de 2, Dönem II'de 2 ve Dönem III'te 3 PDÖ eğitimi uygulanmıştır. $\mathrm{Bu}$ çalışmada tıp fakültesinde uygulanan PDÖ oturumlarına karşı öğrencilerin tutumlarını değerlendirmek amaçlanmıştır.

Araştırma Sorusu: Çanakkale Onsekiz Mart Üniversitesi Tıp Fakültesi dönem II ve III öğrencilerinin PDÖ’ye karşı tutumları nedir?

\section{YÖNTEM}

Çalışma Nicel Araştırmalardan Betimsel araştırma deseninde (kesitsel-tanımlayıcı desen) yapılmışıtır. Çalışmada 2013-2014 Eğitim Öğretim yılında Çanakkale Onsekiz Mart Üniversitesi Tıp Fakültesi Dönem II ve Dönem III öğrencileriyle yapıldı. Çalışmayı kabul eden öğrenciler çalışmaya dahil edildi Dönem II'den 38, Dönem III'den 91 öğrenci çalışmaya katıldı.

\section{Veri Toplama Aracı}

Öğrencilerin PDÖ ye karşı tutumlarının değerlendirildiği çalışmamızda Kemahlı ve Alper tarafindan geçerliliği ve güvenilirliği yapılan Probleme Dayalı Öğrenim Tutum Ölçeği uygulandı. Ölçeğin analiz sonucunda birden çok faktörde toplanan ve faktör yük değerleri 0.30'un altında olan 11 madde ölçekten çıkarılmıştır. Geriye kalan 38 madde altı alt boyutta toplanmıştır. Bu boyutlar problem çözmeye yönelik tutum, grup çalışmasına yönelik tutum, web ortamına yönelik tutum, kendi kendini yönlendirerek öğrenmeye yönelik tutum, ders konusuna yönelik tutum, yönlendiriciye (rehber) yönelik tutum olarak adlandırılmıştır. Ölçeğin Cronbach Alfa Güvenirlik Katsayısı ise 0.86 olarak bulunmuştur. Bu güvenirlik değerleri, ölçekte yer alan maddelerin aynı özelliği ölçtüğü ve ölçek maddelerinin tesadüfi hatalardan olabildiğince arınık olduğu biçiminde yorumlanmıştır (6).

\section{Uygulama}

2013-2014 Eğitim-Öğretim y1lında 05. Mayıs.2014- 09. Mayıs. 2014 tarihinde Dönem II öğrencilerine, daha önceden PDÖ Eğiticiliği konusunda kurs almış öğretim üyesi danışmanlığında, 'Kardiyovasküler Sistem' ile ilgili olarak PDÖ uygulandi.

2013-2014 Eğitim Öğretim yılında 27. Ocak.201431.Ocak.2014 tarihleri arasında, daha önceden PDÖ Eğiticiliği konusunda kurs almış öğretim üyesi danışmanlığında, 'Gastrointestinal Sistem' de PDÖ yapıldığı hafta PDÖ sınavından hemen önce Dönem III öğrencilerine uygulandı.

\section{İzinler}

Çalışma için Çanakkale Onsekiz Mart Üniversitesi İnsan Çalışmaları Etik Kurulu'ndan izin alınarak gerçekleştirildi. Çalışmanın amacı araştırmacılar tarafından anlatıldıktan sonra sözlü ve yazılı onam verilen öğrencilere uygulandı. Probleme Dayalı Öğrenim Tutum Ölçeği geliştiren araştırmacılardan kullanma izin alındı.

\section{İstatistik Analiz}

Çalışmada değişkenlerin ortalama ve frekans değerleri alındı. Tutum ölçeğinin güvenilirliği (coefficient alpa) değeri hesaplandı. Bağımlı değişkenlerin ortalamaları arasındaki fark independent $t$ testi kullanılarak değerlendirildi. Ölçek alt grup analizleri arasındaki ilişki korelasyon ile değerlendirildi. İstatistiksel anlamlılık $\mathrm{p}<0,05$ olarak alınd1.

\section{BULGULAR}

Çalışmaya dönem II öğrencilerinden 38, dönem III öğrencilerinden toplam 91 ögrenci katıldı. Dönem II öğrencilerinden 4 öğrencinin anketlerinde cevaplanmayan soruların fazla olması nedeniyle çıkartıldı ve toplam 125 öğrencinin anketleri değerlendirmeye alındı.

PDÖ Tutum Ölçeğinde toplam 125 öğrencide 38 maddelik testin güvenirlik katsayıs1 (co-efficient alfa) $=0.777 \mathrm{idi}$.

Dönem II ve III öğrencilerinin PDÖ tutum ölçeği alt grup puanlarının dağılımları Tablo 1'de verilmiştir.

Dönem II ve Dönem III öğrencilerinin PDÖ tutum ölçeği alt grup puanlarının arasındaki ilişki Tablo 2'de verilmektedir.

Dönem III öğrencilerinin grup çalışması alt grup puanı Dönem II öğrencilerinden anlamlı daha yüksekti.

PDÖ tutum ölçeğinde Dönem II öğrencilerinin ders konusu alt grup puan ortalaması Dönem III öğrencilerinden anlamlı daha yüksekti $(\mathrm{p}>0.05)$. 
Tablo 1. Dönem II ve III Öğrencilerinin PDÖ Tutum Ölçeği Alt Grup Puan ortalamaları

\begin{tabular}{lcc}
\hline \multirow{2}{*}{ PDÖ tutum Ölçeği } & Dönem II & Dönem III \\
\cline { 2 - 3 } & Ortalama \pm SS [GA] & $17,1 \pm 4,0[4-28]$ \\
Problem çözme & $17,8 \pm 3,2[10-28]$ & $17,1 \pm 6,9[4-40]$ \\
Grup çalışması & $14,3 \pm 5,8[4-27]$ & $13,0 \pm 3,9[2-24]$ \\
Kendi kendini yönlendirme & $12,5 \pm 3,0[4-17]$ & $13,3 \pm 3,2[4-24]$ \\
Web ortamı kullanma & $13,4 \pm 2,1[8-17]$ & $11,8 \pm 4,3[0-20]$ \\
Ders konusu & $13,0 \pm 2,6[6-17]$ & $7,9 \pm 2,5[1-16]$ \\
Yönlendirici & $7,7 \pm 1,3[4-10]$ & $80,1 \pm 16,2[35-152]$ \\
PDÖ tutum ölçeği toplamı & $78,6 \pm 7,7[61-96]$ & \\
\hline
\end{tabular}

SS; Standart sapma, GA; Güven aralığ

Tablo 2. Dönem II ve III öğrencilerinin PDÖ tutum ölçeği alt grup puanlarının dağılımları ile arasındaki ilișki

\begin{tabular}{lll}
\hline PDÖ Tutum Ölçeği & \multicolumn{1}{c}{$\mathbf{t}^{*}$} & \multicolumn{1}{c}{$\mathbf{p}$} \\
\hline Problem çözme & 1.372 & 0,250 \\
Grup çalışması & -1.983 & $0,050^{* *}$ \\
Kendi kendini yönlendirme & 0,073 & 0,942 \\
Web ortamı kullanma & 0,627 & 0,532 \\
Ders konusu & 2,134 & $0,036^{* *}$ \\
Yönlendirici & 0,014 & 0,989 \\
PDÖ tutum ölçeği toplamı & 0,195 & 0,846 \\
\hline * independent t test, ** $<<0,05$ & &
\end{tabular}

* independent $\mathrm{t}$ test, $* * \mathrm{p}<0,05$

\section{TARTIŞMA}

Dönem II ve Dönem III öğrencilerinin PDÖ ye karş1 tutumlarının incelendiği araştırmamızda grup çalışması alt grup puanı Dönem III öğrencilerinde anlamlı derecede daha yüksek olduğu saptandı. Dönem II öğrencilerinde ise ders konusundaki tutumlarının anlamlı yüksek olduğu gözlendi. Dönem III öğrencileri Dönem II öğrencilerine göre tıp fakültesinde daha fazla sayıda PDÖ oturumu deneyimi yaşamışlardır. Bu nedenle grup çalışmasını daha çok benimsemiş olabilirler. Dönem I ve II. sınıfların ders içerikleri temel tıp bilimlerinden oluşmaktadır. Klinik dersler ancak dönem III'ten itibaren verilmektedir. Probleme dayalı öğrenme klinikte görülen olası vakaları yansıtması nedeniyle öğrencilerin ilgisini daha fazla çekmekte ve hedeflere ulaşmada daha etkin olabilmektedir. Bundan dolayı Dönem II öğrencilerinin ders konusundaki farklılıklar, ilk klinik deneyimleri onları daha çok heyecanlandırmış olabilir. Van den Hurk ve ark.ları (7) öğrencilerin araştırma sürecinde elde ettikleri bulguları, izleyen grup çalışmasında diğer öğrencilerle paylaşacak biçimde hazırlandıklarını ve başvurulan bilgi kaynaklarının çeşitliliğinin, oturum sırasında grup tartışmasının genişliğini ve derinliğini etkilediğini vurgulamışlardır. Birçok öğrenme etkinliğini içinde barındıran PDÖ de öğrenciler birbirleri ile iletişim ve etkileşim haline girmekte ve kendi akranları ile bilgilerini farklı kaynaklar çerçevesinde paylaşabilmektedirler.

PDÖ’de öğrencilerin yapılandırdıkları bilgileri daha uzun süre akılda tuttukları, temel tıp ve klinik bilimlerin bütünleştirilmesi gerektiren durumlarda daha iyi yaklaşım uygulayabilmektedirler. Probleme dayalı öğrenmede öğrenciler uygun kaynakları kendileri araştırmakta ve neleri çalışmaları gerektiğine karar vermektedirler (8). Tartışılan problemi yeterince analiz etmek, temel bilgilere veya kavramlara dayalı bazı konuları daha iyi anlamak, problemi daha kapsamlı olarak anlayabilmek için farklı öğrenme kaynaklarına başvurmaktadırlar (9). Tutum ölçeğinde öğrencilerin yönlendirici hakkındaki tutumlarının çok değişkenlik gösterdiği gözlenmektedir. $\mathrm{Bu}$ durum yönlendirici öğretim üyesinin grupla olan iletişimine, davranışlarına ve öğrencilerin beklentilerine göre değişebilmektedir. Özellikle klinik dersleri yeterince almamış olan Dönem II öğrencileri klasik sistemde olduğu gibi yönlendiricinin dersi ve konuyu anlatmasını bekleyebilmektedir. Demirören ve ark. larının (10), bir tıp fakültesi öğrencilerinde PDÖ’nün öğrencilerin öz yeterlilikleri ile ilişkisini belirlemek amacıyla yaptıkları çalışmada; grup çalışmalarının öğrenciler tarafından daha çok benimsendiğini belirtmektedirler. Yine aynı çalıșmada öğrencilerin okudukları yılın PDÖ'ye tutum farkı oluşturmadığını belirtmişlerdir.

Sonuç olarak, öğrenciler PDÖ oturumlarına yönelik eğitim programlarına karşı olumlu tutumlar içinde oldukları gözlenmektedir. Dönem III öğrencileri grup çalışmasını dönem II öğrencilerine göre daha çok benimsemişlerdir. Grup çalışmasının benimsenmesinde daha fazla sayıda PDÖ oturum deneyimi yaşamak önemli olabilir. Bu çalışmanın yapıldığı tıp fakültesinde sınırlı sayıda PDÖ oturumları düzenlendiğinden, tümüyle PDÖ ye karşı tutumlarının olumlu olduğundan bahsetmek hatalı olacaktır.

Teşekkür: Sayın ÇOMÜ Eğitim Bilimleri Fakültesi, Eğitim Programı ve Öğretimi Anabilim Dalı'ndan Doç. Dr. İlke Evin GENCEL hocamıza bizlere vermiş olduğu değerli katkıları nedeniyle teşekkür ederiz.

\section{Çıkar çatışması: Bildirilmedi.}

Finansal destek: Bildirilmedi.

\section{KAYNAKLAR}

1. Loyens SMM, Magda J, Rikers RMJP. Self-directed learning in problem-based learning and its relationships with self-regulated learning. Educational Psychology Review 2008:20(4):411-27.

2. Savery JR, Duffy TM. Problem based learning: An instructional model and its constructivist framework. CRLT Tecnical Report No. 16-01, Bloomington, Indiana University. 2001

3. Spencer JA, Jordan RK. Learner centred approaches in medical education. BMJ. 1999;318: 1280-1283.

4. Özvarış ŞB, Demirel Ö. Öğrenen merkezli tıp eğitimi. Ankara: Türk Tabipleri Birliği Merkez Konseyi, 2002. 
5. Torp L, Sage S. Problems as possibilities: Problem-based learning for K-12 education. USA: Association for Supervision and Curriculum Development, 1998.

6. Kemahlı S, Alper A. Probleme dayalı öğrenmeye yönelik tutum ölçeği. Eğitim Bilimleri ve Uygulama 2006;5(10):191-206.

7. Van den Hurk MM, Dolmans DHJM, Wolfhagen IHAP et al. Impact of individual study on tutorial group discussion. Teaching and Learning in Medicine; 1999;11(4):196-201.

8. Schmidt HG. Educational aspects of problem-based learning. Jochems WMG., ed. Aktiverend Onderwijs. Delft: Delftse Universitaire Pers.1990: 1-16.

9. Schmidt HG. Foundations of problem-based learning: some explanatory notes. Medical Education 1993;27(5):422-32.

10. Demirören M, Turan S, Öztuna D. Medical students' selfefficacy in problem-based learning and its relationship with self-regulated learning. Med Educ Online. 2016:21;30049. 